\title{
Employee Participation and Engagement in Working for the Environment
}

\section{Suzanne Benn, Stephen Teo, Andrew Martin}

\section{Accepted for publication in Personnel Review, 31/7/14}

Purpose: This paper explores the role of specific HRM practices in the implementation of environmental initiatives in terms of their impact on employee attitudes to the organization and to its environmental programme.

Design/methodology/approach: The study used a mixed method approach comprising a survey of 675 employees and 16 semi-structured interviews undertaken across two organizations.

Findings: Survey data, analysed using path analysis, showed that participation in environmental initiatives is directly associated with higher levels of employee engagement with the organization, higher rating of their organization's environmental performance, and lower intention to quit. The qualitative study supports the quantitative data, also highlighting other aspects of environmental initiatives that may affect employee attitudes.

Research limitations/implications: Future study should either collect longitudinal data or rely on data collected from two waves of data collection. Objective performance data should also be collected in order to better understand the causal effect of HRM on environmental performance.

Practical implications: Our findings have implications for the business case for sustainability, providing some evidence that implementing environmental initiatives with HRM support may not only motivate staff around environmental programmes but may provide wider benefits for organizations in terms of overall job satisfaction and employee retention.

Social implications: Successful implementation of environmental management initiatives have both organizational and employee level outcomes. Employees who were more aligned 
with their organizational environmental objectives were found to be more engaged and less likely to quit.

Originality/value: This study provided both quantitative and qualitative empirical evidence to support the importance of integrating the HRM function into the implementation of environmental initiatives. 
This paper explores the role of specific human resource management (HRM) practices in the implementation of environmental initiatives in terms of their impact on employee attitudes to the organization and to its environmental programme. It addresses the lack of understanding of how the HRM system might be used to address the "people factor": the impediment that its employees pose to the environmental or Green performance of organizations (Robertson and Barling, 2013; Stone, 2006).

While the wider HRM literature acknowledges the link between certain HRM practices such as employee participation and positive outcomes for the organization (e.g. Hunton-Clarke et al, 2002), the Green HRM literature is characterized by claims and counter claims (e.g. Jabbour and Santos, 2008b, Jabbour, Santos and Nagano, 2008) and by a dearth of empirically based research papers that link specific HRM practices to the various stages or phases of Green implementation (Jabbour and Santos 2008b, p. 52). As noted in a recent review (Renwick, Redman and Maguire, 2013), much extant knowledge of Green HRM is practice-based and there is a need for more rigorous empirical data on the relationship between various elements of the HRM system such as employee participation or involvement, employee attitudes to environmental initiatives, and whether Green HRM 'pays' through its impact on such factors as employee attraction and retention.

There is considerable evidence that employee participation in environmental initiatives is crucial to their success (Remmen and Lorentzen, 2000; Renwick et al., 2013). This study highlights how participation-oriented managerial practices in the implementation of these initiatives impact on employee perception of the environmental performance of the organization and in turn, on their engagement with and attitude to the organization. It therefore provides the much needed empirical evidence on the critical role of HRM in environmental management. 
The importance of the study also lies in the fact that despite the extensive literature on the topic of a relationship between various HRM interventions and aspects of organizational performance, we do not have a clear understanding of what might motivate a business organization to commit HRM resources to assist in generating and maintaining proenvironmental behaviour. In this paper, we address both the how and why of bringing the HRM system together with the implementation of environmental initiatives.

\section{Employee Attitudes in Environmental Management Initiatives}

A wide and overlapping literature links factors of HRM interest such as employee participation, attitudes, (such as engagement, satisfaction, and support for change initiatives) and turnover (both actual turnover and intention to quit). Claims that high-quality employee participation is a means of achieving organizational effectiveness through facilitating employee commitment and engagement ${ }^{1}$ with the organization (Gollan, 2005) are supported by some empirical evidence. Empowering employees through involvement and participation has been shown to increase job satisfaction and employee retention, paying dividends for the organization. Generalizable relationships significant enough to have substantial practical value have been established between unit-level employee satisfaction-engagement and business-unit outcomes (Harter, Schmidt and Hayes, 2002). Participation, communication, and interaction between groups are found to assist in breaking down barriers between specialists and innovators, thus saving time and building commitment (Hunton-Clarke et al., 2002). Other studies have found that that HRM practices can lower employee intentions to leave, but also that this relationship is partially mediated by organizational commitment (Guchait and Cho, 2010). However, the relationship between attitudes to the workplace and turnover intentions is complex and it has recently been shown that differences in the extent to which job satisfaction systematically improves or declines accounts for change in employees'

\footnotetext{
${ }^{1}$ For the purpose of this paper we assume work engagement to be "a relatively enduring state of mind referring to the simultaneous investment of personal energies in the experience or performance of work" (Christian, Garza and Slaughter, 2011, p. 95).
} 
"turnover intentions" rather than absolute (average) levels of job satisfaction (Chen et al., 2011).

Another body of work relevant to the relationship between employee involvement in and attitudes to the organization shows the importance of participation in gaining support from employees towards new initiatives. This research has been summarised by Oreg, Vakola and Armenakis (2011) in their 60 year review of quantitative studies on change recipients' reactions to change. Drawing on the work of researchers such as Amiot et al. (2006) and Holt et al., (2007) the review finds evidence that change recipients who experienced high levels of participation report higher acceptance of new initiatives and exhibit overall support for the change. From the work of Bartunek et al. (2006), other positive associations are made between participation and understanding the meaning and benefits of a change initiative (Bartunek et al., 2006). Steel and Lloyd's study (1988) also provides evidence that participation results in increased attachment to the organization. Macey and Schneider (2008) in their recent review proposed that employee engagement can be enhanced with participative management and job involvement practices.

\section{HR Practices and Green Outcomes}

The relationship between participation or involvement, employee engagement with the organization, job satisfaction, support for new initiatives, and employee retention found in the general HRM literature has not been systematically investigated in specific terms in relation to the implementation of organizational Greening.

If we look to some of the relevant studies in the wider organizational Greening literature we see evidence of trends that we can build on to develop constructs for more systematic empirical testing. In their systematic review of Green HRM, Renwick et al. (2013) apply the Ability-Motivation-Opportunity theory to examine different types of HRM practices that could be classified as Green HRM as they were found to have an impact on 
environmental management. An example of Green HRM includes those practices that relate to workplace involvement and participation. The literature has also shown that employee involvement and participation in environmental initiatives is positively related to key aspects of environmental management systems (Remmen and Lorentzen, 2000; Renwick et al., 2013) such as efficient use of resources, waste reduction, and pollution reduction in the workplace.

Remmen and Lorentzen (2000) found that employee participation in the implementation of a cleaner technology project can increase employee understanding of environmental problems and issues and had a strong effect on changing work routines and increasing environmental consciousness. Paille et al.'s (2014) study in the Chinese context showed that internal environmental concern moderates the effect of strategic human resource management on organizational citizenship behavior for the environment. The research of Kitazawa and Sarkis (2000) showed that employee empowerment and participation in decision-making are crucial elements in managing continuous source reduction programmes because they increase their employees' buy-in to the environmental challenges of the organization. Zutshi and Sohal (2004) also found that employee involvement in planning of environmental policy, environmental management systems (EMS) processes and supporting programmes was strongly associated with morale building within the company. These studies indicate that high levels of employee participation and involvement are positively associated with environmental performance. This is achieved as employees develop a better understanding of the rationale behind the environmental goals and environmental performance of the organization.

The implementation of environmental management systems has been shown to be influenced by the extent to which Green HRM practices are being implemented (Wagner, 2013). As employees became more involved and participated more strongly in environmental management, employees felt more motivated, which subsequently led to a higher level of 
work engagement. Cantor, Morrow, and Montabon (2012) have shown higher levels of employee engagement and commitment are seen on green initiatives. Employee involvement and participation are both examples of high involvement HRM practices and they have been shown to enhance employees' motivation and commitment towards their organization (Gollan, 2005; Wilkinson, Hill and Gollan, 2001). Employee involvement and participation are also considered to be aspects of Green HRM as these were found to positively associate with environmental performance (Renwick et at., 2013). Hence, we propose the following three hypotheses:

Hypothesis 1. There is a positive relationship between employee participation and involvement in environmental initiatives and employee engagement.

Hypothesis 2. There is a positive relationship between employee participation and involvement in environmental initiatives and assessment of organizational environmental performance.

Hyothesis 3. There is a positive relationship between employee engagement and their assessment of organizational environmental performance.

A recent meta-analytical review of the relationships between engagement and job satisfaction has shown that these two concepts are different and positively correlated (Christian, Graza and Slaughter, 2011). While participative practices enhance engagement (see Macey and Schneider, 2008), job satisfaction is also positively correlated with participative practices (Cox, Marchington, and Suter, 2009).

The introduction of environmental initiatives such as environmental standards can facilitate increased communication between workers and lead to knowledge development (Delmas and Pekovic, 2013). Participatory approaches to knowledge development have also been linked empirically to job satisfaction. Teh and Sun (2012) empirically tested the relationships showing that when employees are involved in their job higher job satisfaction 
results. This positive relationship is related to their knowledge sharing behaviour. Research has also shown that while employees possess important contextual knowledge and the importance of process, intra-organizational and external knowledge make the role of specialist staff critically important for environmental improvements. Such improvements often require a combination of more than one knowledge type (Rothenberg, 2003). Hence, we expect participation and engagement to have a practical role to fulfil in regard to innovation for environmental improvement. This leads us to the following hypotheses:

Hypothesis 4. There is a positive relationship between employees' engagement and the level of their job satisfaction.

Hypothesis 5. There is a positive relationship between employees' satisfactory assessment of their organization's environmental performance (such as their unit's performance outcomes and organizational environmental performance outcomes) and their level of job satisfaction.

The work of Chen et al. (2011) that associates changes in job satisfaction to employee retention is complemented in the environmental responsibility literature by studies (such as Strandberg, 2009), which link the integration of environmental responsibility into organizational values to enhanced employee recruitment and retention. Pride in the organization in general has been shown to predict organizational commitment (Boezeman and Ellemers, 2008) and perceived alignment of corporate with individual employee values around environmental sustainability has been suggested as a key source of business advantage, a source of job satisfaction and a means of attracting and retaining talented staff (Dunphy, Griffiths and Benn, 2007).

If there are connections between engagement and job satisfaction and/or between perceptions of environmental performance and job satisfaction, it would seem reasonable to suggest engagement, high perceptions of environmental performance, and job satisfaction 
may engender higher levels of loyalty and morale (Bhatnagar, 2007), something which might be indicated by a negative link with an intention to leave the organization. This leads us to our final two hypotheses that link into a series of causal hypotheses:

Hypothesis 6. There is a negative relationship between employees' satisfactory assessment of their organization's environmental performance (such as their unit's performance outcomes and organizational environmental performance outcomes) to their intention to quit.

Hypothesis 7. There is a negative relationship between employees' level of job satisfaction to their intention to quit.

Insert Figure 1 about here

\section{Methods}

Based on the need to develop a deep understanding of the phenomena being researched (Morse and Niehaus, 2009), we adopted a two-phase mixed method research design in the form of an online questionnaire accompanied by a qualitative study. Our aim to explore relationships between employee participation or involvement, employee attitudes to environmental initiatives and the impact on such factors as employee attraction and retention cannot be divorced from complex considerations such as cultural characteristics. Hence, as suggested by Creswell and Plano Clark (2007, p. 5) it seemed that quantitative and qualitative approaches, in combination, could provide us with a better understanding of the research problems than either approach alone.

Accordingly, we took one of the mixed methods approaches recommended by Creswell and Plano Clark (2007) where we followed up our quantitative data collection with interviews with a few key respondents within our survey samples in order to provide further 
explanation of some key points that emerged in the quantitative study. Cresswell $(2009,211)$ terms this methodological approach a 'sequential exploratory strategy' and argues it is suitable when a qualitative approach can be used to explain quantitative data, or when the researchers see the need for more detailed information about the organisational context, particularly when there are issues of cultural context, which may be difficult to test quantitatively. Hence the two forms of data are separate and while coming from different philosophical positions may be usefully connected.

Our selected organizations for the study are two Australian organizations: Educator and Engineer, for anonymity named here after their advertised core function. Educator is a major Australian technical college with 2,700 staff. Engineer is an engineering consultancy with 8000 staff. The use of two cases provides for analytic benefits (Yin, 2003). An important factor in selecting the organizations is the fact that they are both large organizations well advanced in implementing an environmental programme. Each organization is a member of a voluntary sustainability programme part funded by government, designed to progress environmentally sustainable business practices and each has a documented environmental policy. Each organization has the means for their staff to participate in environmental initiatives. For example, a certain level of staff participation is a requisite of the government-funded sustainability programme. This programme is designed to raise the environmental capacity of the member organisations such as Engineer and Educator through participation in sustainability workshops and other events. Engineer also has a number of operational green initiatives such as water and energy reduction systems that staff may engage in. Staff make suggestions concerning a range of incentive schemes designed to reduce waste and resource use, and sustainability is referred to as a key aspect of client services. Educator is certified to ISO 14000, provides training to other educational institutions on environmental auditing, has developed numerous new environmental courses 
and widely embeds sustainability in existing educational products. It has won multiple sustainability awards. Staff participate in suggestions for how environmental sustainability can be embedded in the organization's educational products as well as making suggestions concerning operational improvements.

\section{Quantitative phase}

Our quantitative data were derived from a survey with banks of items designed to test the key variables hypothesized. For Educator we received 201 responses and 436 responses for Engineer. The sample comprised of senior management ( 6 per cent), middle management (16.1 per cent), supervisory management (21.3 per cent), and the remaining were nonmanagement employees. The majority of the respondents were male (62 per cent). Most of them were in the age group between 20 and 34 years old ( 30.9 per cent), followed by those between 35 to 45 years old (23.1 per cent).

Survey data were input into SPSS v.19 for Windows to conduct exploratory factor analysis (EFA), cluster analysis, and descriptive statistics. EFA was undertaken using principal axis factoring and oblimin rotation while confirmatory factor analysis was conducted using IBM PAWS 19.0 and AMOS. SmartPLS v2 3.0 (Ringle, Wende and Will, 2005) was used to analyze the path model (note: internal reliability coefficients and average variance estimates are reported in Table 1).

\section{Measures}

Participation in environmental initiatives (reflective scale). Three items were used to operationalize employees' participation in the implementation of environmental initiatives. These items were adopted from a survey conducted by the NSW Department of Environment, Climate Change and Water "Who Cares about Water and Climate Change" survey (2007), also utilised in subsequent surveys, and the Wackernagel and Rees (1996) Ecological Footprint calculator, as utilized by the Victorian Government's Environmental Planning 
Authority (EPA Victoria, 2006). Employees were asked to rate on a five point scale ranging from " $1 "=$ not at all to " $5 "=$ a lot. These were "To what extent do you feel that you could offer the organization ideas about how to improve its environmental performance?", "If you did have ideas, to what extent do you think that the organization would listen to you?" and "To what extent do you think the organization might act on your suggestions?".

Organizational Environmental Performance (reflective scale). As the case study organizations originated from the public and private sector, they do not have the same objective performance measures. Hence, we decided to use subjective, perceptual performance indicators. We used three items to measure employees' perception of their organization's environmental performance. The items were "In comparison with its competitors in the same industry, how would you rate your organization's environmental performance?", "In comparison with other business units/departments within your organization, how would you rate your business unit/department's environmental performance?" and "In general terms, how would you personally rate your organization's environmental goals?" These items were rated on a five point scale, from "1"=very poor to " $5 "=$ very strong.

Employee Engagement (reflective scale). Four items developed by JRA (2007) were used to measure employee engagement in Australia and New Zealand. These items were similar to those used in the literature to measure employee engagement (see reviews by Christian et al., 2011). The items were "I look for ways to do my job more effectively", "I feel inspired to go the extra mile to help this organization succeed", "I feel a sense of commitment to this organization", and "Overall, I would recommend this organization as a great place to work". Respondents were asked to rate the items on "1" = Completely agree to "7"= Completely disagree. Low scores indicate high engagement. 
Job satisfaction. We used a single global item to determine job satisfaction. Job Satisfaction was rated on "1" = Completely agree to "7"= Completely disagree. Respondents were asked to respond to "Overall, I am satisfied with my job". A low rating signified a higher level of job satisfaction. Research has shown that job satisfaction can be adequately measured using a single item (see Wanous, Reichers and Hudy, 1997).

Intention to Quit (reflective scale). Respondents were asked to respond to a two-item scale, which measured their intention to quit the organization. These items were "I am actively looking for a job outside this organization" and "I am seriously thinking about quitting my job”. Intention to Quit was measured on a seven point scale, with higher scores signifying higher intention to quit. These items were adopted from JRA (2007).

Validity and reliability. Our sample size of 637 respondents is more than sufficient to achieve a medium effect size of 0.80 for a path model with four predictors (Green, 1991, p. 503). Following Ringle et al. (2005), the significance of PLS parameter estimates were determined by using the bootstrap option incorporated within the SmartPLS (Ringle et al., 2005) software. A bootstrap procedure with 500 sub-samples was undertaken to provide extra confidence that the results are not sample specific. Discriminant validity of the reflective constructs is assessed by using Fornell and Larcker's (1981) rule that the Average Variant Estimates (AVEs) of both constructs should be larger than the square of the correlation between them (reported in Table 1).

Common method variance was checked with two different tests. First, Harman's expost one factor test was used to ensure that the current study did not suffer from common method variance (Podsakoff and Organ, 1986). All the variables used in the study were entered into an unrotated factor analysis to determine the number of factors. The analysis showed that the single largest factor explained 35 per cent. A single common latent factor analysis was also computed using AMOS. The analysis showed that the paths accounted for 
less than 10 per cent of the variance in the common latent factor. These checks provided us with additional confidence that common method bias was not a concern.

As PLS models do not have any goodness of fit indices such as AMOS, we evaluated the quality of the proposed structural model using R-square of the dependent variables and the Stone-Geisser Q-square test for predictive relevance (Chin, 2010). Since the values were stable for both omission distances and the majority of the Q-squares were greater than zero, we were confident that the model had predictive stability.

\section{Qualitative phase}

The qualitative study aimed at contextualizing and expanding on the factors identified above in relation to the seven hypotheses. We utilized in-depth interviews in order to obtain thick descriptions of staff experiences that might allow us some insight into the workplace context for each organization (Morse and Niehaus, 2009).

Altogether 16 semi-structured interviews from across the two organizations were undertaken. Respondents included individuals who, by virtue of position or job description, would be most likely to participate in or be responsible for managing the implementation of the environmental initiative in each organization. In our interviews and subsequent analysis we probed more deeply around our core themes of participation, employee engagement and perceived environmental performance, but particularly probed for understandings that might inform us on the organizational culture around environmental sustainability. We were interested in which HRM is being embedded in the implementation of environmental initiatives. This is critical as variability in sustainability culture could have a major influence on how employees react to environmental implementation (e.g., Linnenluecke and Griffiths, 2010) and, therefore, on their motivation around environmental programmes.

Our key intention with these individuals was to understand employee responses in the context of their organizational sustainability cultures, a complex issue very difficult to 
explore in a quantitative approach (Dunphy et al., 2007). We also analyzed the formal discourses of each of the organizations, via examination of their websites and other publicly available information in order to explore potential impacts of differences between espoused and actual sustainability values.

We used the sustainability phase model (Benn et al, 2014; Dunphy et al., 2007) to classify the sustainability culture of each organization. According to this model, in the efficiency phase, for example, the organization has a sustainability culture characterized by an instrumental focus on reducing waste and increasing process and materials efficiencies. In the strategic phase the sustainability culture is signified by an emphasis on innovation and broad support from across the organization, including from leadership, for the strategic opportunities of sustainability and its long-term importance to the organization. This phase is notable for an alignment of formal and informal discourses around sustainability, reflecting management decisions to embed sustainability in the core business model (Dunphy et al., 2007).

\section{Results}

\section{Quantitative Phase}

Means, standard deviations, AVEs, and correlations between the variables are reported in Table 1 . The model has discriminant validity as the correlation matrix shows that the square roots of the AVEs reported (in the diagonal) are greater than the corresponding off-diagonal correlation coefficients. We followed the calculation of global goodness-of-fit index by Tenenhaus, Vinzi, Chatelin and Lauro (2005) to compute a global goodness-of-fit index of 0.474, suggesting a high goodness of fit (Wetzels, Odekerken-Schröder and van Oppen, 2009, p. 187). R-square of the dependent variable, Intention to Quit, was 35.4 per cent. 
Results of the path analysis are reported in Table 2 while Figure 2 showed the results in diagrammatic format. With the exception of one hypothesis (Hypothesis 5), all of the hypotheses were supported. Our results show that participation in environmental initiatives is associated with employee engagement, which is associated with job satisfaction. Participation in environmental initiatives is directly associated with perceptions of environmental performance but this relationship is also mediated by levels of job satisfaction.

Insert Table 2 about here

Insert Figure 2 about here

Figures 3 and 4 showed the differences in the path model in each case study organization. Educator respondents reported higher levels of participation, engagement, indicated higher assessment of the organization's performance, and evidenced less intention to quit. Higher levels of participation were reflected in higher levels of employee engagement, and in both organizations higher participation and higher engagement resulted in improved perceptions of organizational environmental performance. In both cases, higher rates of engagement led to increased job satisfaction.

Insert Figures 3 and 4 about here 


\section{Qualitative study}

The qualitative phase of the study was designed to assist in explaining the context of the differing levels of employee characteristics described in the quantitative phase. The differences (see Figure 3) whereby Educator respondents reported higher levels of participation and engagement associated with higher assessment of the organization's performance and less intention to quit are suggestive of different organizational cultures or subcultures (Linnenluecke, Russell, and Griffiths, 2009). The differences between the samples in the quantitative study imply that the two organizations may have different 'sustainability cultures', relating to the extent to which sustainability strategies and practices are embedded in organisational practices (Benn et al, 2014; Dunphy et al, 2007) and which have been shown to impact on levels of participation and employee attitudes (Benn et al, 2014; Dunphy et al, 2007; Russell and McIntosh, 2011). The results of the qualitative study, designed to explore the sustainability culture of the two organizations, confirmed this suggestion. As discussed below, the strategy of Educator management had been to embed environmental sustainability into its core business, hence explaining the higher levels of participation and engagement perceived in this organization.

Although the formal organizational discourses of the two organizations on websites and other organizational documents, for example, their partnerships with the government department, were quite similar in terms of their espoused commitment to sustainability, the informal discourse through the interviews reveal marked differences between how the employees of the two organizations (see Table 3) saw the environmental performance of their organization. In short, the interviews revealed very different sustainability cultures (Linnenluecke and Griffiths, 2010). 


\section{Environmental Sustainability Objectives and Approaches of Educator}

Within Educator, supporting findings from the quantitative study, participating and engaged Educator respondents perceived that Educator is a leader in environmental management, aligning themselves with its formal discourse and espoused organizational values. As evidenced by respondent quotes in Table 3, Educator purports to be attempting to embed sustainability strategically and utilizing participatory approaches in the core functions of the organization and would be classified according to the Dunphy et al (2007) phase model as being in the strategic phase of sustainability. Such a strategy of embedding environmental sustainability thus further explains why engaged individuals may remain loyal to their organization, as suggested by our quantitative data. Supporting the findings from the quantitative study that highly engaged individuals show a positive response to the organization's environmental goals and performance, overall these respondents perceived that they shared values with the organization and that Educator's commitment to sustainability added to their job satisfaction. So in this case we see a strong alignment between the individual and their sustainability values with both the organizational formal and informal discourses - a highly motivating set of factors for the employee around environmental initiatives and their implementation.

\section{Environmental Sustainability Objectives and Approaches of Engineer}

Engineer did not show the same alignment of informal and formal discourse around sustainability aims and objectives. In contrast to the organization's public discourse expressed on website statements our interview analysis suggests that employees do not see Engineer as an environmental "leader". They see the organization as following client 
demand rather than sustainability leading it in a more strategic direction. In Table 3 we describe examples of such responses as having an 'instrumental (client) focus' or as demonstrating an 'efficiency focus'. Interviewees generally perceived the environmental commitment of Engineer to be 'weak'.

\section{Discussion and Implications}

The aim of the current study is to examine how HRM practices and approaches such as employee participation and involvement may affect employee attitudes to the implementation of environmental initiatives and to the organization in general. Results of the path analysis showed across both organizations support for all of the research hypotheses except for Hypothesis 5.

As indicated by the path analyses, there were some slight differences in the findings between Engineer and Educator. In Educator, employees with higher perception of organization environmental performance report higher job satisfaction and less intention to quit while in Engineer, these two paths were not found. These findings were reflected in the qualitative study as employees in Educator reported higher level of participation in EMS while in Engineer, their employees were not provided the opportunity to participate in EMS. The qualitative study revealed that these differences were due to the sustainability culture in Educator, where management had recognised the importance of developing organizationwide commitment to sustainability practices. It highlights the significance for senior management to actively use HRM practices as the means to enhance employees' job satisfaction and reduce their intention to turnover, while showing the importance of embedding a sustainability culture based in a participatory approach.

From the qualitative study, while Educator respondents highlighted an understanding that sustainability was embedded in the core business of the organization and that this was a positive in terms of their commitment to the organization, within Engineer, where 
environmental sustainability strategies and practices were focussed on utility and efficiency, there was little perceived alignment of personal values with the sustainability values of the organization. With Educator, there was a much higher level of alignment between the formal and informal discourses around sustainability. In other words, sustainability culture in Educator is more strongly embedded and more strategically significant than is the case with Engineer, which we classified more in the efficiency phase of sustainability, according to the Dunphy et al (2007) framework.

Bringing together the two research phases it can be seen that, despite having very different sustainability cultures and being in different phases of sustainability, the relationship between our variables held although we note a stronger relationship between participation and environmental performance and more engaged individuals with the organization with the stronger sustainability culture (Educator), as shown in Figure 4.

Educator is a public sector organization, which perhaps explains either or both the differences in sustainability culture and relationship between our variables. However, this does not detract from the finding that if espoused and actual (as perceived by employees) sustainability values are in alignment and there is employee participation in environmental initiatives then it seems we have a strong motivating force for the environmental initiative itself as well as for the organization as a whole.

Hence the results from the qualitative study extend understandings from the quantitative study because they indicate that the level of alignment between what is espoused formally by the organization in terms of its environmental goals and strategies and how this is played out in the actual culture of the organization as reflected in the informal discourse of the employees impacts on the attitudes of employees and their motivation or engagement. In other words, levels of involvement, participation, engagement, job satisfaction, and intention 
to quit in relation to environmental initiatives need to be considered in the context of the sustainability culture of the organization.

From an HRM perspective, our findings suggest a stronger instrumental link between support for participatory approaches to implementation of Green initiatives, employee engagement, and employee attraction and retention if the organization is embedding environmental sustainability in its strategies and practices. Our qualitative data also suggests that employees with strong levels of personal commitment to sustainability are more likely to be attracted to and remain with an organization if it is seen to be on the "journey" to sustainability (Milne, Kearins and Walton, 2006).

These findings also have important implications to support the business case for sustainability, for which there have been claims (Wilkinson et al., 2001) and counter claims (such as Orlitzky, Schmidt and Rynes, 2003) in the literature. Specifically, our findings contribute to this debate by providing the empirical evidence that if employees are given the opportunity by senior management to participate and be involved in the implementation of environmental initiatives they will be more engaged in the organization. This finding was also supported by the cluster analysis where highly engaged employees were more satisfied with their job as they were more involved - a finding that corroborates the engagement literature (see Christian et al., 2011).

\section{Limitations and Future Research Implications}

Our findings indicate that the boundaries between environmental and HRM functions of the organization need to be less proscribed, with each set of professionals aware of the others' key practices. As well, however, as Jabbour and Santos (2008a) have identified, the theory that informs each field of practice needs to be more inclusive. We have shown that people respond to being involved in environmental initiatives and that this seems to occur more where there has been an attempt to embed a culture of strategic sustainability. This 
suggestion, however, needs to be tested in a wider comparative case-based study using test items specifically designed to measure the efficiency and strategic dimensions of the Dunphy et al. (2007) model.

We note that our two organizations can both be classified as knowledge-based organizations, with their core function being the development and transmission of knowledge. Yahya and Goh (2002) assert the strong link between HRM and knowledge management. They have shown that a knowledge organization requires a different management approach than a non-knowledge organization and that the role of HRM is thus unique. The similarity in our results could perhaps thus be explained - suggesting the need for wider survey-based, cross-sectoral studies to test our findings across other organizations that are not classified as knowledge organizations. This study could likewise have benefitted from inclusion of data relating the age gender and ethnic background of respondents (in these case omitted under the terms of our access for reasons of privacy). The issue of "intention to quit" may be worthy of further consideration in later studies since we have to acknowledge that interpretation of such intentions can be highly complex and may reflect, for example, only short-term intentions (Bhatnagar, 2007).

We accept that our study shows a lack of objective longitudinal data. Future study should either collect longitudinal data or rely on data collected from two waves of data collection. However, we note that the current study relied on a mixed-method study, which meant that the qualitative data was used to triangulate the quantitative findings. While it must be accepted that complex factors associated with organizational culture - subcultures, hierarchies, organizational roles, personal networks, and personal factors such as ethnicity, gender, and age - may affect the generalizability of our findings (e.g., Linnenluecke et al., 2009), nevertheless, the causal connections revealed in this study suggest a "short cut" or key 
focus for adapting HRM practices in a manner that offers strong potential for stimulating environmentally-oriented behaviors.

Literature in the field suggests that HRM specialists have limited understanding of how to apply their expertise to fostering the implementation of Green initiatives and that insignificant consideration was given to environmental issues as an integrated aspect of organizational practice. The study identifies a positive role for HRM to play in interactions with environmental initiatives such as the implementation of environmental management systems in regard to employees' active input and participation in decision-making. The study suggests that HRM strategies do not require a "specialized" or "specialist" approach, but rather a more familiar approach - identifying a positive role for employee involvement and participation in interactions with Green initiatives in regard to employees' input and participation in decision-making.

Consistent with the findings of Rothenberg (2003) and Rothenberg and Becker (2004), it might appear that "participation" involves more than learning about an EMS or environmental proactivity in general (c.f. Ramus and Steger, 2000) and refers more specifically to providing an opportunity for employees to contribute in a "hands on" role (not necessarily an innovative role) applying existing skills and localized knowledge or practical critique. Equally consistent is the proposition that appropriate "engagement" arises from the useful deployment of existing skills and localized knowledge, encouraging participants to assume personal responsibility for programme implementation. With engagement that involves personal responsibility, one associates the development of a level of pride in achievement that is likely therefore to bolster the engaged employees' perceptions of environmental achievement of the organization. 


\section{REFERENCES}

Amiot, C., Terry, D., Jimmieson, N., and Callan, V. (2006). 'A longitudinal investigation of coping processes during a merger: Implications for job satisfaction and organizational identification'. Journal of Management, 32, 552-574

Bartunek, J. M., Greenberg, D. N., and Davidson, B. (1999). 'Consistent and inconsistent impacts of a teacher-led empowerment initiative in a federation of schools'. Journal of Applied Behavioral Science, 35, 457-478.

Bartunek, J. M., Rousseau, D. M., Rudolph, J. W., and DePalma, J. A. (2006). 'On the receiving end: Sensemaking, emotion, and assessments of an organizational change initiated by others'. Journal of Applied Behavioral Science, 42, 182-206.

Benn, S., Dunphy, D. and Griffiths, A. (2014). Organizational Change for Corporate Sustainability. $3^{\text {rd }}$ edition, New York, London: Routledge.

Bhatnagar, J. (2007). 'Talent management strategy of employee engagement in Indian ITES employees: key to retention'. Employee Relations, 29(6), 640-663.

Boezeman, E. J. and Ellemers, N. (2008). 'Pride and respect in volunteers' organizational commitment'. European Journal of Social Psychology, 38, 159-172.

Cantor, D. E., Morrow, P. C. and Montabon, F. (2012). 'Engagement in environmental behaviors among supply chain management employees: An organizational support theoretical perspective'. Journal of Supply Chain Management, 48: 33-51.

Chen, G., Ployhart, R.E., Anderson, N., Thomas, H.C., and Bliese, P.D. (2011). 'The power of momentum: A new model of dynamic relationships between job satisfaction change and turnover intentions. Academy of Management Journal, 54(1), 159-181.

Chin, W.W. (2010). 'How to write up and report PLS analyses'. In Chin W. W. (Ed.), Handbook of Partial Least Squares Analysis: Concepts, Methods and Applications, 645-688. Berlin, Heidelberg: Springer. 
Christian, M.S., Garza, A.S. and Slaughter, J.E. (2011). 'Work engagement: A quantitative review and test of its relations with task and contextual performance'. Personnel Psychology, 64(1), 89-136.

Colakoglu, S., Lepak, D. P. and Hong, Y. (2006). 'Measuring, HRM effectiveness: Considering multiple stakeholders in a global context'. Human Resource Management Review, 16(2), 209-218.

Cox, A., Marchington, M. and Suter, J. (2009). 'Employee involvement and participation: developing the concept of institutional embeddedness using WERS2004'. The International Journal of Human Resource Management, 20, 2150-2168.

Creswell JW and Plano Clark VL (2007) Designing and Conducting Mixed Methods Research, Thousand Oaks, CA: Sage.

Daily, B. F. and Huang, S-C. (2001). 'Achieving sustainability through attention to human resource factors in environmental management'. International Journal of Operations and Production Management, 21(12), 1539-1552.

Delmas, M. A., and Pekovic, S. (2013). 'Environmental standards and labor productivity: Understanding the mechanisms that sustain sustainability'. Journal of Organizational Behavior, 34, 230-252.

Dunphy, D., Griffiths, A. and Benn, S. (2007). Organizational Change for Corporate Sustainability. New York, London: Routledge.

EPA Victoria (2006). Ecological Footprint: Measuring our impact on the environment. http://www.epa.vic.gov.au/ecologicalfootprint/: State Government of Victoria (accessed 15 July 2012).

Fornell, C. and Larcker, D. F. (1981). 'Evaluating structural equation models with unobservable variables and measurement error'. Journal of Marketing Research, 18(1), 39-50. 
Gollan, P. J. (2005). 'High involvement management and human resource sustainability: The challenges and opportunities'. Asia Pacific Journal of Human Resources, 43(1), 1833.

Green, S. B. (1991). 'How many subjects does it take to do a regression analysis?' Multivariate Behavioral Research, 26, 499-510.

Guchait, P. and S. Cho (2010). 'The impact of human resource management practices on intention to leave of employees in the service industry in India: the mediating role of organizational commitment'. International Journal of Human Resource Management. 21, 1228-1247

Harter, J. K., Schmidt, F. L. and Hayes, T. L. (2002). 'Business-unit-level relationship between employee satisfaction, employee engagement, and business outcomes: A meta-analysis'. Journal of Applied Psychology, 87(2), 268-279.

Holt, D. T., Armenakis, A. A., Feild, H. S., and Harris, S. G. (2007). 'Readiness for organizational change: The systematic development of a scale'. Journal of Applied Behavioral Science, 43, 232-255.

Hunton-Clarke, L., Wehrmeyer, W., Clift, R., McKeown, P. and King, H. (2002). 'Employee participation in environmental initiatives: Facilitating more environmentally conscious decision-making in innovation'. Greener Management International, 40, 45-56.

Jabbour, C. J. C. and Santos, F. C. A. (2008a). 'The central role of human resource management in the search for sustainable organizations'. International Journal of Human Resource Management, 19(12), 2133-2154.

Jabbour, C. J. C. and Santos, F. C. A. (2008b). 'Relationships between human resource dimensions and environmental management in companies: proposal of a model'. Journal of Cleaner Production, 16, 51-58. 
Jabbour, C. J. C., Santos, F. C. A. and Nagano, M. S. (2008). 'Environmental management system and human resource practices: Is there a link between them in four Brazilian companies?' Journal of Cleaner Production, 16, 1922-1925.

Jacobs, E. and Roodt, G. (2007). 'The development of a knowledge sharing construct to predict turnover intentions'. Aslib Proceedings, 59(3), 229-248.

JRA. (2007). Employee Engagement: Driving Organization Performance. Auckland: JRA.

Kitazawa, S., and Sarkis, J. (2000). The relationship between ISO 14000 and continuous source reduction. International Journal of Operations and Production Management, 20(2), 225-248.

Linnenluecke, M. K. and Griffiths, A. (2010). 'Corporate sustainability and organizational culture'. Journal of World Business, 45, 357-366.

Linnenluecke, M. K., Russell, S. V. and Griffiths, A. (2009). 'Subculture and sustainability practices: the impact on understanding corporate sustainability'. Business Strategy and the Environment, 18(7), 432-452.

Macey, W.H. and Schneider, B. (2008). 'The meaning of employee engagement'. Industrial and Organizational Psychology, 1, 3-30.

Milne, M., Kearins, K. and Walton, S. (2006). 'Creating adventures in wonderland: The journey metaphor and environmental sustainability’. Organization, 13(6), 801-839.

Morse, J. M. and Niehaus, L. (2009). Mixed Method Design: Principles and Procedures. Walnut Creek, Cal.: Left Coast Press.

NSW Department of Environment Climate Change and Water. (2007). Who Cares about Water and Climate Change in 2007: A survey of NSW people's environmental knowledge, attitudes and behaviour (http://www.environment.nsw.gov.au/resources/ community/07545WCWaterClimate07.pdf: NSW Government, accessed 08 Dec 2010). 
Oreg, S., Vakola, M. and Armenakis (2011). 'Change recipients' reactions to organizational change: A 60-year review of quantitative studies.' The Journal of Applied Behavioural Science, 47(4), 461-524.

Orlitzky, M., Schmidt, F. L. and Rynes, S. L. (2003). 'Corporate social and financial performance: A meta-analysis'. Organization Studies, 24(3), 403-441.

Paille, P., Chen, Y., Boiral, O. and Jin, J. (2014). 'The impact of human resource management on environmental performance: An employee-level study'. Journal of Business Ethics, 121(3), 451-466.

Podsakoff, P. M. and Organ, D. W. (1986). 'Self-report in organizational research: Problems and prospects'. Journal of Management, 12(4), 533-544.

Prasad, P. and Elmes, M. (2005). 'In the name of the practical: Unearthing the hegemony of pragmatics in the discourse of environmental management'. Journal of Management Studies, 42(4), 845-867.

Ramus, C. A. and Steger, U. (2000). 'The roles of supervisory support behaviors and environmental policy in employee "ecoinitiatives" at leading-edge european companies'. Academy of Management Journal, 43(4), 605-626.

Remmen, A., and Lorentzen, B. (2000). 'Employee participation and cleaner technology: learning processes in environmental teams'. Journal of Cleaner Production, 8(5): 365-373.

Renwick, D. W. S., Redman, T., and Maguire, S. (2013). 'Green human resource management: A review and research agenda'. International Journal of Management Reviews, 15, 1-14.

Ringle, C. M., Wende, S. and Will, A. (2005). SmartPLS 2.0 v3 (beta). www.smartpls.de: SmartPLS Community. 
Robertson, J. L. and Barling, J. (2013). ‘Greening organizations through leaders' influence on employees' pro-environmental behaviors'. Journal of Organizational Behavior, 34, 176-194.

Rothenberg, S. (2003). 'Knowledge content and worker participation in environmental managament at NUMMI'. Journal of Management Studies, 40(7), 1783-1802.

Rothenberg, S., and Becker, M. (2004). 'Technical assistance programs and the diffusion of environmental technologies in the printing industry: The case of SME's'. Business and Society, 43(4),366-397.

Russell, S. and McIntosh, M. (2011). 'Changing culture for corporate sustainability'. In N. M. Ashkanasy, C.P.M. Wilderon and M.F. Peterson (Eds) Handbook of Organizational Culture and Climate, pp 373-411, USA: Sage Publications

Steel, R. P., and Lloyd, R. F. (1988). Cognitive, affective, and behavioral outcomes of participation in quality circles: Conceptual and empirical findings. Journal of Applied Behavioral Science, 24, 1-17.

Stone, L. (2006.). 'Limitations of cleaner production programmes as organizational change agents. II: Leadership, support, communication, involvement and programme design'. Journal of Cleaner Production, 14, 15-30.

Strandberg, C. (2009). The Role of Human Resource Management in Corporate Social Responsibility: Issue Brief and Roadmap Report for Industry Canada/Industrie Canada. Burnaby, BC: Strandberg Consulting.

Teh, P-L. and Sun, H. (2012). 'Knowledge sharing, job attitudes and organisational citizenship behaviour'. Industrial Management \& Data Systems, 112, 64 - 82.

Tenenhaus, M., Vinzi, V. E., Chatelin, Y.-M. and Lauro, C. (2005). PLS Path Modeling. Computational Statistics and Data Analysis, 48(1), 159-205. 
Wackernagel, M. and Rees, W. (1996). Our Ecological Footprint: reducing human impact on the earth. Gabriola Island, B.C., Canada New Society Publishers.

Wagner, M. (2013). 'Green' human resource benefits: Do they matter as determinants of environmental management system implementation?' Journal of Business Ethics, 114, $443-456$.

Wanous, J., Reichers, A. and Hudy, M. (1997). 'Overall job satisfaction: How good are single-item measures?' Journal of Applied Psychology, 82(2), 247-252.

Wee, Y. S. and Quazi, H. A. (2005). 'Development and validation of critical factors of environmental management'. Industrial Management and Data Systems, 105(1), 96114.

Wetzels, M., Odekerken-Schröder, G. and van Oppen, C. (2009). 'Using PLS Path Modeling for assessing hierarchical construct models: Guidelines and empirical illustration'. MIS Quarterly, 33(1), 177-195.

Wilkinson, A., Hill, M. and Gollan, P.( 2001). 'The sustainability debate'. International Journal of Operations and Production Management, 21(12), 1492-1502.

Yahya, S. and Goh, W-K. (2002). 'Managing human resources toward achieving knowledge management'. Journal of Knowledge Management, 6(5), 457-468.

Yin, R. (2003). Case Study Research: Design and Methods, Thousand Oaks, London and New Delhi: Sage Publications

Zutshi, A. and Sohal, A. (2004). 'Adoption and maintenance of environmental management systems: Critical success factors'. Management of Environmental Quality, 15(4), 399419. 
Figure 1 Proposed Path Model

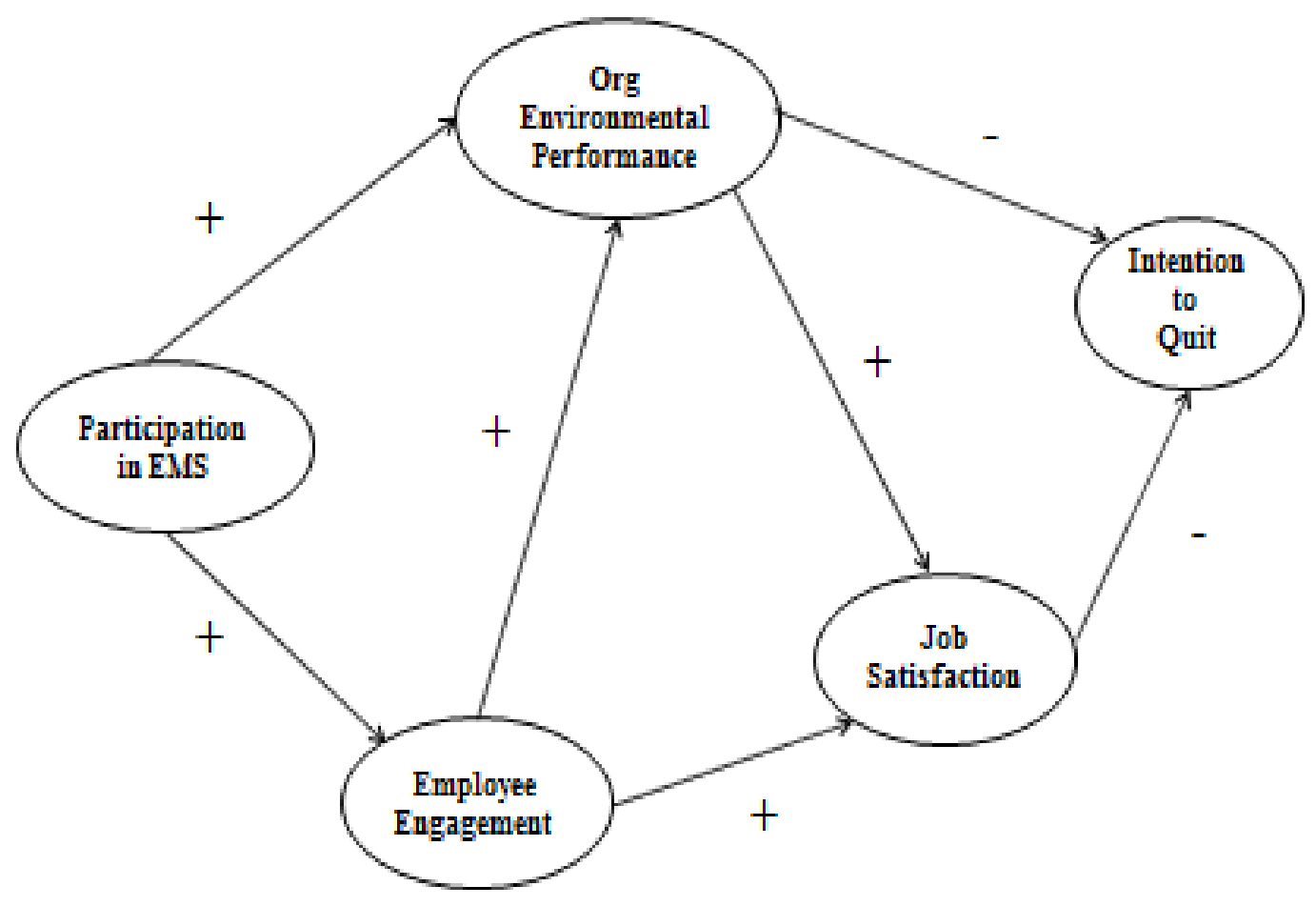


Figure 2 Results of Partial Least Squares Analysis

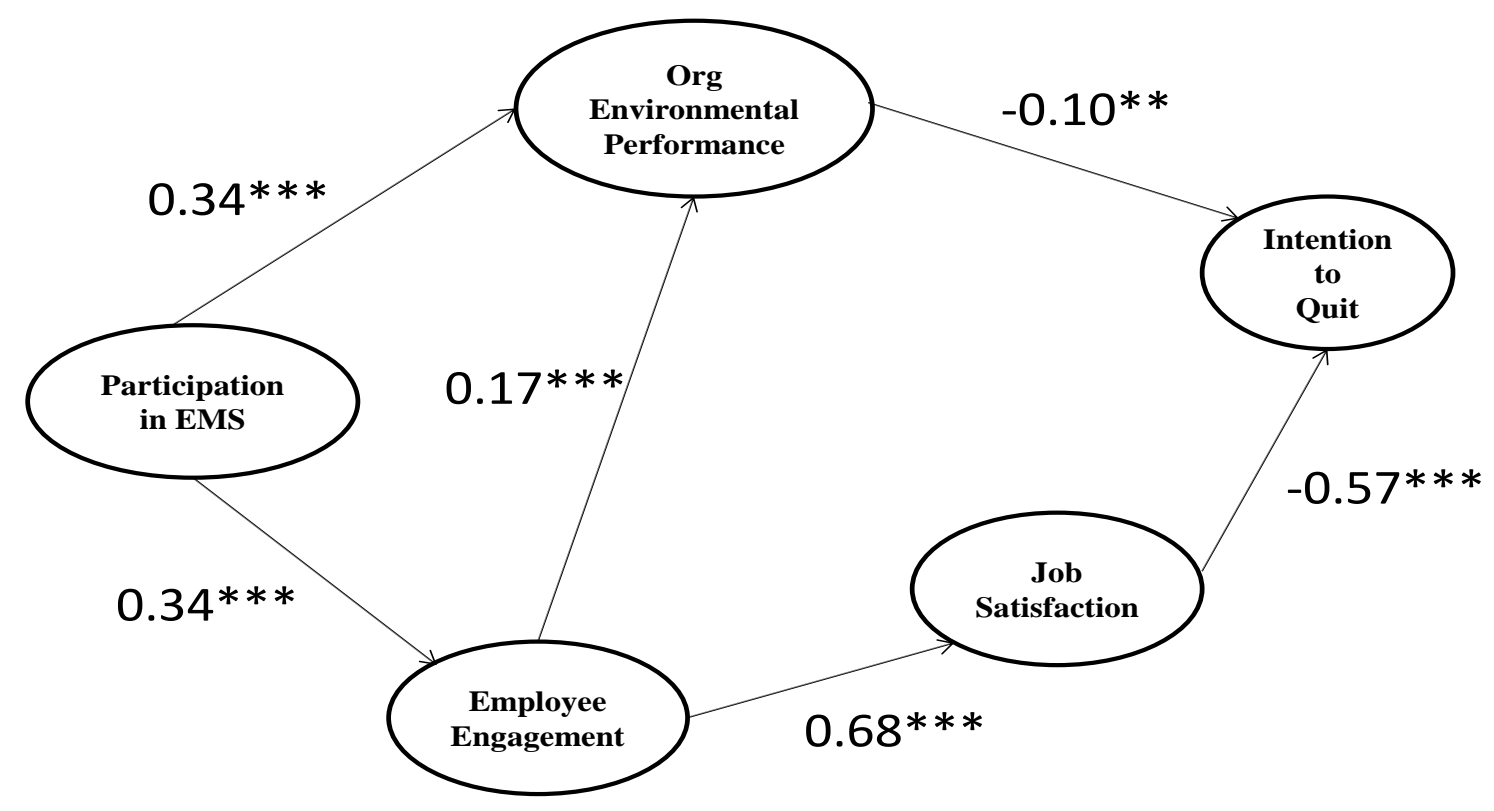

$* * \mathrm{p}<.01 ; * * * \mathrm{p}<.001$ 
Figure 3 Results of Path Analysis for Engineer

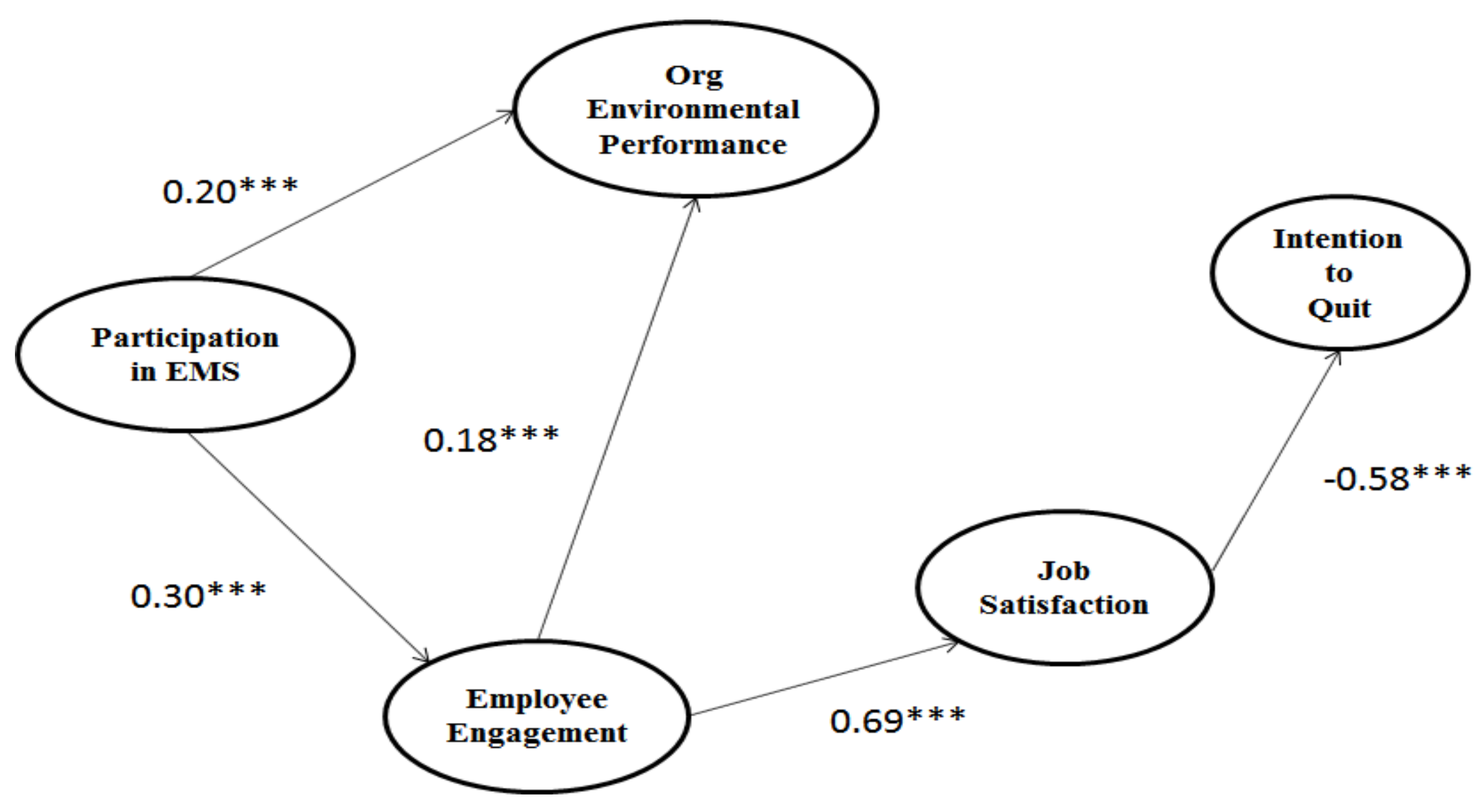

$* * \mathrm{p}<.01 ; * * * \mathrm{p}<.001$ 
Figure 4 Results of Path Analysis for Educator

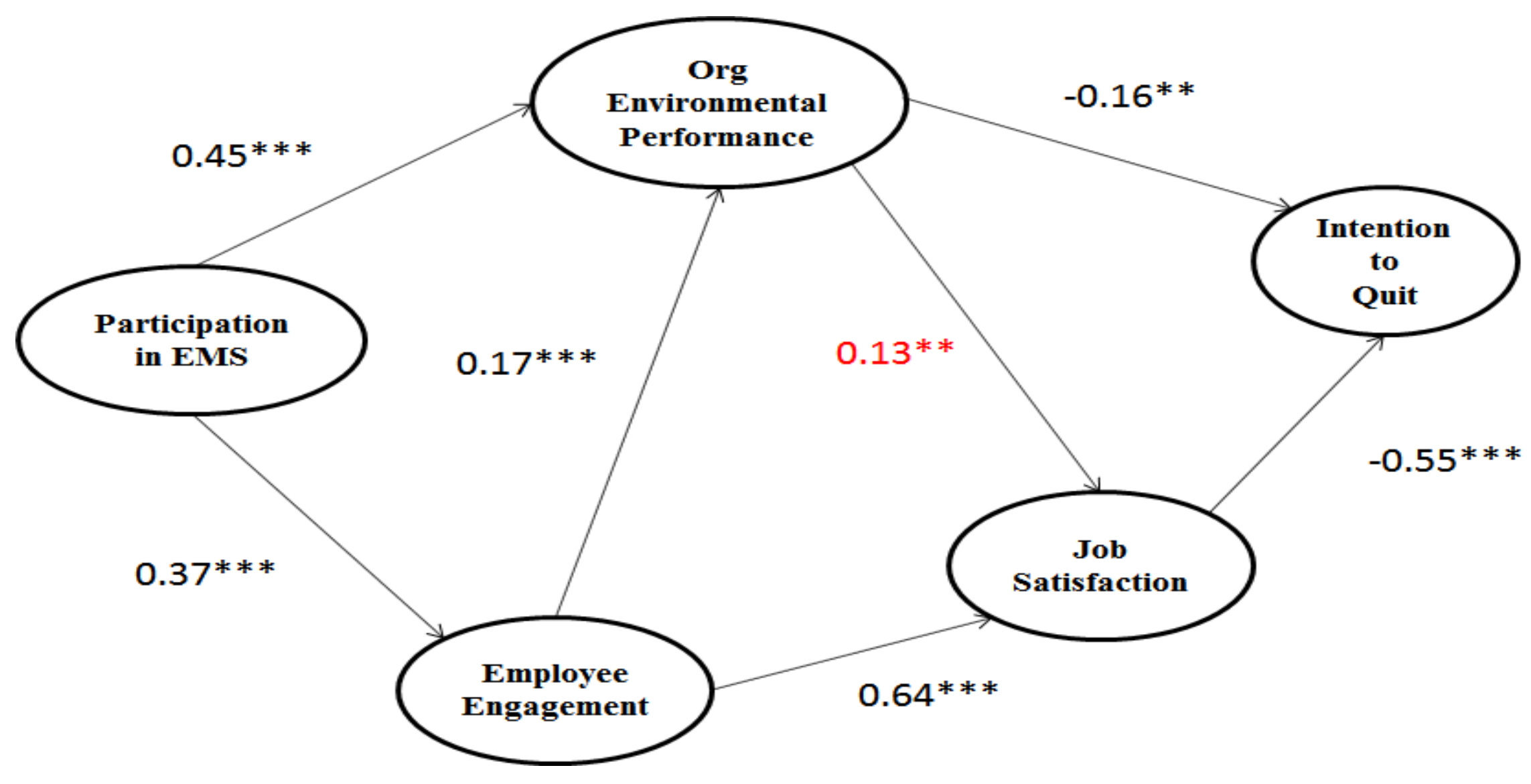

$* \mathrm{p}<.01 ; * * \mathrm{p}<.01 ; * * * \mathrm{p}<.001$ 
TABLE 1 Mean, Standard Deviation, AVE and Correlations

\begin{tabular}{|c|c|c|c|c|c|c|c|c|c|c|}
\hline & M & $\mathrm{SD}$ & $\alpha$ & AVE & 1 & 2 & 3 & 4 & 5 & 6 \\
\hline $\begin{array}{l}\text { 1. Level of } \\
\text { appointment }\end{array}$ & 3.23 & .96 & -- & -- & 1.00 & & & & & \\
\hline $\begin{array}{l}\text { 2. Participation in } \\
\text { EMS }\end{array}$ & 3.17 & .72 & .81 & .63 & $-.19 * * *$ & .79 & & & & \\
\hline $\begin{array}{l}\text { 3. Employee } \\
\text { Engagement }\end{array}$ & 2.10 & .82 & .80 & .50 & $.19 * * *$ & $-.28 * * *$ & .71 & & & \\
\hline $\begin{array}{l}\text { 4. Org Env } \\
\text { Performance }\end{array}$ & 3.52 & .62 & .85 & .85 & -.04 & $.34 * * *$ & $-.24 * * *$ & .81 & & \\
\hline 5. Job Satisfaction & 2.26 & 1.11 & -- & -- & .07 & $-.23 * * *$ & $.67 * * *$ & $-.14 * * *$ & 1.00 & \\
\hline 6. Intention to Quit & 2.22 & 1.37 & .92 & .85 & $-.08 *$ & $.16 * * *$ & $-.49 * * *$ & $-.18 * * *$ & $-.57 * * *$ & .92 \\
\hline
\end{tabular}

Note: Fornell and Larcker (1981) test of discriminant analysis square roots of AVEs are shown in diagonal row as italicized

Engagement and Job Satisfaction items were rated on " $1 "=$ Completely agree to " $7 "=$ Completely disagree while participation items were rated on " $1 "=$ not at all to "5" = a lot. Intention to Quit has been reverse coded, so that higher scores signify higher intention to quit.

$* \mathrm{p}<.05 ; * * \mathrm{p}<.01 ; * * * \mathrm{p}<.001$ 
TABLE 2 Results of Path Coefficients

\begin{tabular}{|l|c|c|}
\hline Paths & Path coeff & t-statistic \\
\hline H1. Participation $\rightarrow$ Engagement & 0.34 & $10.03^{* * *}$ \\
\hline H2. Participation $\rightarrow$ Environmental Perf & 0.34 & $9.11^{* * *}$ \\
\hline H3. Engagement $\rightarrow$ Environmental Perf & 0.17 & $4.67^{* * *}$ \\
\hline H4. Engagement $\rightarrow$ Job Satisfaction & 0.68 & $21.26^{* * *}$ \\
\hline H5. Environmental Perf $\rightarrow$ Job Satisfaction & 0.01 & 0.43 \\
\hline H6. Environmental Perf $\rightarrow$ Intention to Quit & -0.10 & $3.10^{* *}$ \\
\hline H7. Job Satisfaction $\rightarrow$ Intention to Quit & -0.57 & $15.89^{* * *}$ \\
\hline
\end{tabular}

Note:

$* * \mathrm{p}<.01 ; * * * \mathrm{p}<.001$ 
TABLE 3 Themes Emerging From Interviews

\begin{tabular}{|c|c|c|}
\hline & Educator & Engineer \\
\hline $\begin{array}{l}\text { Sustainability aims and } \\
\text { Objectives: Formal } \\
\text { discourse }\end{array}$ & $\begin{array}{l}\text { 'At [Educator] environmental sustainability is a way of thinking } \\
\text { and doing that is embedded in every aspect of the Institute's } \\
\text { operations. As an educational provider, we are committed to } \\
\text { enabling others to do the same, not just to meet basic standards } \\
\text { or mandatory requirements but to reach a stage where all } \\
\text { business decisions are approached through the lens of } \\
\text { sustainability' (Educator Website, 2012). }\end{array}$ & $\begin{array}{l}\text { 'We are an innovative organization committed to helping } \\
\text { our clients achieve unprecedented and sustained business } \\
\text { results' (Engineer Website, 2008). }\end{array}$ \\
\hline $\begin{array}{l}\text { Sustainability aims and } \\
\text { Objectives: Informal } \\
\text { discourse }\end{array}$ & $\begin{array}{l}\text { 'What we ultimately want is to have it so you can't get your } \\
\text { diploma from (the Educator) unless you are demonstrating } \\
\text { competency in environmental management within that particular } \\
\text { area of qualification, as well as always providing the means and } \\
\text { ways so that all students have the opportunity to experience that } \\
\text { knowledge even if it's not part of that particular training } \\
\text { package. What I'd be striving for is to do precisely that' } \\
\text { (Educator Director, the Educator, interviewed September 10, } \\
\text { 2008). }\end{array}$ & $\begin{array}{l}\text { Instrumental (client) focus } \\
\text { '[Engineer] is not a leader of companies. It is a follower } \\
\text { and it does what its clients ask it to do. It's very difficult to } \\
\text { go out there and say we'll build you a sustainable steel } \\
\text { plant when no one wants a sustainable steel plant. And I } \\
\text { see sustainability being asked for in as little as } 10 \% \text { of } \\
\text { clients' documentation at best. Very weak' (Sustainable } \\
\text { Development Manager, the Engineer, interviewed July 31, } \\
\text { 2008). } \\
\text { Efficiency focus } \\
\text { 'A lot of people don't see the difference between } \\
\text { sustainability and what they have always done, which is to } \\
\text { look for efficiency' (Engineer-sponsored PhD student, } \\
\text { interviewed August 1, 2008). }\end{array}$ \\
\hline $\begin{array}{l}\text { Participation: } \\
\text { Formal discourse }\end{array}$ & $\begin{array}{l}\text { 'Effective communication and collaboration underpins our } \\
\text { success. Your input to our approach is vital' (Strategic } \\
\text { Directions, the Educator, 2007-2010). }\end{array}$ & $\begin{array}{l}\text { 'We ask you to rate our performance on specific categories } \\
\text { applicable to your project. We especially welcome } \\
\text { additional comments and information that will help us to } \\
\text { fine tune our current practices to better serve you' } \\
\text { (Engineer website, 2008). }\end{array}$ \\
\hline Participation: Informal & $\begin{array}{l}\text { 'If staff have something they want to share or are interested in } \\
\text { they always know there's an avenue to come and share these }\end{array}$ & $\begin{array}{l}\text { 'The way that change occurs in this organisation is that } \\
\text { someone in a reasonably senior position that has a lot of }\end{array}$ \\
\hline
\end{tabular}




\begin{tabular}{|l|l|l|}
\hline discourse & Educator & Engineer \\
& $\begin{array}{l}\text { ideas. I think it has to be completely open. And if you get lots of } \\
\text { people then you just need to find a new venue and that would be } \\
\text { fantastic!' (Environmental Officer, interviewed August 18, } \\
\text { 2008). }\end{array}$ & $\begin{array}{l}\text { trust in the organization sees a vision of the future that's } \\
\text { different from the current vision' (Sustainable } \\
\text { Development Manager, the Engineer, interviewed July 31, } \\
\text { 2008). }\end{array}$ \\
\hline $\begin{array}{l}\text { Commitment and } \\
\text { engagement: } \\
\text { Informal discourse }\end{array}$ & $\begin{array}{l}\text { 'The key reason I came to the Educator from (previous place of } \\
\text { employment) was because they had the commitment to the } \\
\text { ISO14001, which gives a lot of validity to the work that I do' } \\
\text { (Environment Officer, the Educator, interviewed August 18, } \\
\text { 2008). }\end{array}$ & $\begin{array}{l}\text { On one hand they [Engineer] have invested this money } \\
\text { into sustainability but they haven't come up with any } \\
\text { strong declaration or commitment for everyone to see. } \\
\text { Sustainability is not critical, whilst other elements are seen } \\
\text { as critical such as financial return and safety. But } \\
\text { sustainable development is not there among the top } \\
\text { ranking objectives' (Engineer sponsored PhD researcher, } \\
\text { interviewed August 1, 2008). }\end{array}$ \\
\hline
\end{tabular}

